\title{
nature
}

27 September 2001 Volume 413 Issue no 6854

\section{Japan's beef scandal}

The detection of BSE in Japan last week raises the prospect of vCJD to follow. The history of government handling of human health crises gives little basis for confidence that appropriate preventative measures will be taken.

$\mathrm{B}$ eef is a favourite food in Japan, especially among the young, with a steady yearly demand of about 1.5 million tonnes. The recent discovery of a cow suffering from bovine spongiform encephalopathy (BSE) has therefore caused considerable concern (see page 337). People are starting to dread the appearance of new variant Creutzfeldt-Jakob disease (vCJD), the human nerve-degenerating disease believed to be caused by eating certain parts of BSE-afflicted cows.

The fears are all the more palpable because the Japanese government has shown that it cannot be trusted to do the right thing in such public-health cases.

The government's complicity in covering up, and thereby spreading, mercury poisoning in Minamata during the 1950s and 1960s is the most famous example. Although researchers identified fish contaminated with industrial effluvium from a local factory as the culprit, the government took no action for years. Victims died or suffered lifelong disabilities in the following decades, and suits against the government and the company continue to this day.

The government has been slow to act in other cases as well. HIVtainted blood was given to haemophilia patients in 1985 and 1986, long after they should have switched to heat-treated blood that was known to be safe. In 1997, the health ministry belatedly banned the import and use of contaminated German dura mater grafts, used in brain surgery, almost 10 years after the US Food and Drug Administration had taken action against them. The grafts inflicted another deadly CJD-variant on a reported 76 (and rising) brain-surgery patients, many of whom could have been saved by prompt action.

The Japanese government seems to be up to its old tricks again with BSE. A European Commission report of a survey on the risk of BSE in various countries was effectively blocked when the Japanese government insisted that it did not deserve the high-risk rating that the commission was planning, according to commission officials. And when the existence of the mad cow was finally admitted by the government, agriculture ministry officials reportedly claimed to have burned the cow to prevent transmission - only to admit later that it had been passed on for feed production. Now they are scrambling to identify the cause, and the amount of spread in food chains.

During the early 1990s, Britain scandalously dumped much of its unwanted meat and bone meal on Japan and other Asian countries. Now there is much concern that BSE cases will spread throughout Asia, especially Indonesia and Thailand, which imported large amounts of meat and bone meal. Japan should have the economic might and regulatory know-how to implement the expensive but necessary tests and make adequate restrictions. It could have stood as a model, showing its less prosperous Asian neighbours how to nip a potential epidemic in the bud. Instead, Japan has fallen behind. While other countries implement restrictions on feeding ruminants to ruminants, Japan has been content with non-binding 'administrative guidelines' which have reportedly been ignored in certain cases. Only after finding its first mad cow did Japan tighten up these guidelines into a compulsory regulation.

Japan criticized the European Commission's report because of an alleged lack of evidence, saying it would only alarm the public. "Lack of scientific evidence" was also the excuse made for not taking action in the earlier cases. The more likely reason is the tight connection between government and industry or government and healthcare institutions. These cosy relationships, often enhanced by a ministry official's retiring to a position in a large company, are cause for alarm.

Japan needs unbiased opinions, such as those the European Commission tried to provide. Perhaps then it would cease making inappropriate judgements that turn out to be fatal for some citizens.

\section{Reviewing cancer and immunology}

Introducing two new Nature journals.

C olorectal cancers are the third most frequent cancer worldwide, with increasing incidence in the developing world. More positively, they provide a vivid example of how serendipity and clinical observation can lead to fundamental biomedical insights. Long-term use of nonsteroidal anti-inflammatory drugs was serendipitously found to reduce colorectal cancer incidence in large clinical trials. By taking these clinical results back into the lab, researchers identified an enzyme, cyclooxygenase 2 (COX-2), that is overproduced in colorectal cancers and is clearly involved in tumour development. Selective COX-2 inhibitors reduce the number of polyps in people with familial adenomatous polyposis, an inherited predisposition to colorectal cancer, so may be of significant clinical benefit in preventing colorectal cancer in these individuals.

This synergy of disciplines, not to mention the vast flow of information that cancer specialists have to battle with, highlights a prime motivation of one of two Nature review journals being launched on
1 October. Nature Reviews Cancer aims to help all cancer researchers not only to develop an overview of their own areas of expertise but also to understand new opportunities emerging in others.

Interdisciplinary motivations have also stimulated the launch of Nature Reviews Immunology. Immunology is a diverse and growing discipline, but it is also at risk of fragmentation. It faces major challenges. The threat from autoimmune diseases is ever-increasing; we do not yet know how to stimulate the immune system to combat cancer; infectious diseases are on the rise and the need for efficacious vaccines is ever-present; and much remains to be learned about overcoming organ-specific transplant rejection. And the statistics speak for themselves: $30 \%$ of all deaths in 2000 were attributable to infectious diseases, and 2.7 million people alone died from HIV infection.

Immunologists and cancer researchers clearly have a lot of work to do. The new journals are intended to help them and their disciplines thrive. 